\title{
Heterogeneity of the Ehlers-Danlos Syndrome: Description of Three Clinical Types and a Hypothesis to Explain the Basic Defect(s)
}

\author{
A. P. BARABAS, * M.B., F.R.C.S.
}

Brit. med. F., 1967, 2, 612-613

The Ehlers-Danlos syndrome is an inherited disorder of connective tissue; it belongs to the same group of diseases as Marfan's syndrome, osteogenesis imperfecta, and Hurler's syndrome (McKusick, 1966). Recently the heterogeneity of some of the syndromes became apparent-for example, Hurler's syndrome was shown to comprise at least five different genotypes (McKusick, 1966).

However, Ehlers-Danlos syndrome is still regarded as a single disease entity, but evidence is here given that at least three types are included in the present clinical definition of the syndrome.

\section{Diagnosis and Criteria}

The diagnosis of Ehlers-Danlos syndrome was made on clinical signs, since there are no specific laboratory, radiological, or consistent histological findings. All patients reported

\begin{tabular}{|c|c|c|c|c|c|c|c|}
\hline $\begin{array}{l}\text { Case } \\
\text { No. }\end{array}$ & Family & $\begin{array}{l}\text { Age : } \\
\text { Se: }\end{array}$ & and & $\begin{array}{c}\text { Pre- } \\
\text { maturity }\end{array}$ & $\begin{array}{c}\text { Severity } \\
\text { of Skin } \\
\text { and Joint } \\
\text { Involvement }\end{array}$ & $\begin{array}{l}\text { Varicose } \\
\text { Veins }\end{array}$ & $\begin{array}{c}\text { Arterial } \\
\text { Ruptures }\end{array}$ \\
\hline \multicolumn{8}{|c|}{ Group 1} \\
\hline \begin{tabular}{r|}
1 \\
2 \\
3 \\
4 \\
5 \\
6 \\
7 \\
8 \\
9 \\
10 \\
11 \\
12 \\
13 \\
14 \\
15
\end{tabular} & $\begin{array}{l}\mathbf{A} \\
\mathbf{A} \\
\mathbf{B} \\
\mathbf{B} \\
\mathbf{B} \\
\mathbf{B} \\
\mathbf{C} \\
\mathbf{C} \\
\mathbf{C} \\
\mathbf{D} \\
\mathbf{D} \\
\mathbf{F} \\
\mathbf{G} \\
\mathbf{H} \\
\mathbf{I}\end{array}$ & $\begin{array}{r}50 \\
57 \\
48 \\
24 \\
5 \\
2 \\
44 \\
18 \\
12 \\
22 \\
2 \\
16 \\
10 \\
28 \\
24\end{array}$ & $\begin{array}{l}\mathbf{F} \\
\mathbf{M} \\
\mathbf{F} \\
\mathbf{F} \\
\mathbf{M} \\
\mathbf{M} \\
\mathbf{M} \\
\mathbf{F} \\
\mathbf{F} \\
\mathbf{F} \\
\mathbf{F} \\
\mathbf{M} \\
\mathbf{F} \\
\mathbf{F} \\
\mathbf{F}\end{array}$ & $\begin{array}{l}+ \\
+ \\
? \\
+ \\
+ \\
+ \\
+ \\
+ \\
+ \\
+ \\
+ \\
+ \\
+ \\
+ \\
+\end{array}$ & $\begin{array}{c}+++ \\
+++ \\
++++ \\
++++ \\
++++ \\
? \\
+++ \\
+++ \\
+++ \\
+++ \\
? \\
+++ \\
+++ \\
+++ \\
++++\end{array}$ & $\begin{array}{l}= \\
\overline{-} \\
\bar{?} \\
\underline{?} \\
= \\
\bar{?} \\
\bar{?} \\
=\end{array}$ & $\begin{array}{l}\bar{z} \\
\bar{z} \\
\bar{z} \\
= \\
z \\
= \\
= \\
=\end{array}$ \\
\hline \multicolumn{8}{|c|}{ Group 2} \\
\hline $\begin{array}{l}16 \\
17 \\
18 \\
19 \\
20 \\
21 \\
22 \\
23 \\
24 \\
25\end{array}$ & $\begin{array}{l}\mathrm{J} \\
\mathbf{K} \\
\mathrm{K} \\
\mathrm{K} \\
\mathrm{L} \\
\mathrm{L} \\
\mathrm{M} \\
\mathrm{M} \\
\mathrm{M} \\
\mathrm{N}\end{array}$ & $\begin{array}{l}52 \\
23 \\
53 \\
31 \\
50 \\
15 \\
50 \\
22 \\
12 \\
45\end{array}$ & $\begin{array}{l}\mathbf{F} \\
\mathbf{M} \\
\mathbf{M} \\
\mathbf{M} \\
\mathbf{M} \\
\mathbf{F} \\
\mathbf{F} \\
\mathbf{F} \\
\mathbf{F} \\
\mathbf{M}\end{array}$ & $\begin{array}{l}\bar{z} \\
\bar{z} \\
\bar{z} \\
\bar{z}\end{array}$ & $\begin{array}{l}++ \\
++ \\
++ \\
++ \\
++ \\
++ \\
+ \\
+ \\
+ \\
++\end{array}$ & $\begin{array}{c}+ \\
\pm \\
++ \\
++ \\
+ \\
? \\
= \\
+ \\
++\end{array}$ & $\begin{array}{l}\bar{z} \\
= \\
= \\
= \\
= \\
=\end{array}$ \\
\hline \multicolumn{8}{|c|}{ Group 3} \\
\hline $\begin{array}{l}26 \\
27\end{array}$ & $\mathbf{O}$ & $\begin{array}{l}32 \\
30\end{array}$ & $\underset{\mathbf{F}}{\mathbf{F}}$ & $\stackrel{?}{-}$ & $\stackrel{+}{+}$ & $\overline{-}$ & $\begin{array}{l}++t \\
++t\end{array}$ \\
\hline
\end{tabular}

Prematurity (less than $5 \frac{1}{16}$. (2.5 kg.) birth weight): + premature; - no premature; ? no information.

Severity of skin and joint involvements (arbitrary grades): ++++ gross +++ moderate; ++ mild; + very mild; $?$ too young (less than 3 years old). Varicose veins: + yes; - no; ? less than 16 years old; ++ had operation fo varicosities.

here had a tendency to excessive bruising, laceration of the skin after minor trauma, skin hyperextensibility, and joint hypermobility. Characteristic thin hyperpigmented scars were also found in every patient. Skin biopsies were carried out in seven patients (Cases 1, 4, 7, 10,13, 26, and 27, Table I): in every case the microscopical appearances were compatible with the diagnosis of Ehlers-Danlos syndrome.

- Surgical Registrar, the Royal Postgraduate Medical School, Hammersmith Hospital, London W.12. Present address: The Norfolk and Norwich Hospital, Norwich, NOR 53A.

All patients were examined by me. Most of them were seen repeatedly, and some were followed up for two years.

\section{Results of Investigations}

Table I summarizes the more important findings. In eight families (A, B, C, D, J, K, L, and $M$ ) more than one of their members were found to be affected. There was a remarkable similarity in the clinical picture within each family (minimal intrafamilial variation). The 27 patients examined fell into three distinct clinical groups.

Group 1. The "Classical" Type (Cases 1-15).-Thirteen of these patients were born prematurely, owing to premature rupture of foetal membranes (Barabas, 1966). In all these patients skin and joint involvements were severe. No varicose veins or arterial ruptures occurred in this group.

Group 2. Mild or "Varicose" Type (Cases 16-25).-In this group no patient was born prematurely and the skin and joint manifestations were not severe. Two of the five male patients played rugby regularly at school. Five of the 10 patients had severe bilateral varicose veins and three of them had required operations, one male patient at the early age of 18 . Another male patient (Case 17) showed minor varicosities. One family $(M)$, with very mild skin and joint manifestations and no varicose veins, probably belongs to another subgroup.

Group 3. "Arterial" Type (Cases 26 and 27).-These were two unrelated women who had suffered from repeated severe arterial ruptures (see Table II). Bruising was the paramount sign in these patients, and they showed spontaneous ecchymoses during menstruation. Their skin was soft and so transparent that the subdermal venous pattern was unusually obvious. Hyperextensibility of the skin was slight, and joint hypermobility was limited to the hands. Severe unexplained attacks of abdominal pain troubled both patients. (Detailed case histories with histological findings will be published elsewhere.)

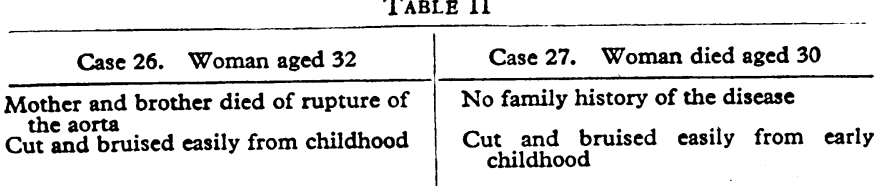

Reasons for Hospital Admissions

Age 20: Rupture of iplenic artery; Age 12: Large haematoma in right iliac Age 20: Rupture of splenic artery; Age 25: Large femoral haematoma; required blood transfusion;
E.D.S. diagnosed

Age 27: Recurrent severe abdominal pain; allinvestigations negative

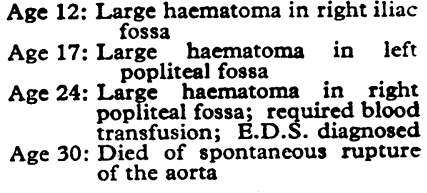

Discussion

\section{Heterogeneity}

The marked clinical variability of Ehlers-Danlos syndrome is well known, and hitherto this has been attributed to variable expressivity of the same gene. Premature rupture of foetal membranes, leading to premature birth of the affected babies 
(Barabas, 1966), varicose veins (Sæmundsson, 1956), and rupture of large arteries (McFarland and Fuller, 1964), are well-documented manifestations in this syndrome.

However, this study is the first attempt to analyse the distribution of the different varieties and complications in a considerable number of patients. It has been shown that the same clinical picture appears in affected members of each family, and that certain clinical signs and complications regularly occur together. These observations gain practical importance, especially when applied to the group with the only potentially fatal complications of Ehlers-Danlos syndrome-the rupture of large arteries.

Arterial rupture as a complication of Ehlers-Danlos syndrome was first reported by Mories (1960). Since then at least six further examples have been described (McFarland and Fuller, 1964 ; Lynch et al., 1965 ; André et al., 1965 ; McKusick, 1966). Except in two patients (André et al., 1965 ; Lynch et al., 1965), the diagnosis of Ehlers-Danlos syndrome was made retrospectively after the fatal arterial rupture.

The present series is unique because it includes two patients who survived several arterial ruptures. They were compared with 25 patients without a history of arterial rupture. Though the two patients showed clinical and histological features well within the present definition of Ehlers-Danlos syndrome, they differed from the 25 in important aspects such as their liability to gross bruising, the peculiar transparency of their skin, the minor degrees of skin hyperextensibility and joint hypermobility, and their attacks of severe abdominal pain.

It is suggested, therefore, that Ehlers-Danlos syndrome with arterial complications should be regarded as a separate entity, and an impending arterial catastrophe need not be anticipated in those patients differentiated in groups 1 and 2 above.

\section{Basic Defect}

The basic defect in Ehlers-Danlos syndrome has long been, and still is, a matter for argument. Most investigators think that it lies in the collagen (McKusick, 1966), but others believe it is a primary elastic-fibre defect (Goltz and Hult, 1965). Wechsler and Fisher (1964) showed convincingly that there are no microscopical or electron-microscopical defects in either fibre. Jackson and Bentley (1967) suggested that the defect in
Ehlers-Danlos syndrome lies at a high level of organization of the collagen fibres. Their hypothesis is an elaboration of Jansen's (1955) defective collagen "wickerwork" theory. According to them, in this high-level binding the collagen fibrils interact with the various mucopolysaccharides and mucopolysaccharide-protein complexes of the "ground substance."

In the three types of Ehlers-Danlos syndrome three different mucopolysaccharides or mucopolysaccharide-protein complexes may be at fault. All three would lead to some bruising and scarring of the skin and to some joint hypermobility ; but each defect would cause a specific weakness, such as the gross capillary and arterial wall fragility in the " arterial " type.

\section{Summary}

Twenty-seven patients with Ehlers-Danlos syndrome belonging to 15 families were examined. Three distinct familial clinical types were found-"classical," "varicose," and "arterial."

A new hypothesis regarding the basic defect(s) in EhlersDanlos syndrome is discussed.

I am grateful to Professor A. M. Boyd, Dr. M. C. G. Israëls, and Professor J. H. Kellgren, of the Manchester Royal Infirmary, for allowing me to study cases under their care. My thanks are also due to Mr. F. S. Steven, of the Medical Biochemistry Department, Manchester University, for helpful discussions on the biochemical aspects. I also thank the Arthritis and Rheumatism Council for giving me a grant.

\section{REFERENCES}

André, R., Duhamel, G., Vergoz, D., and Lavallee, R. (1965). Bull. Soc. méd. Hôp. Paris, 116, 971

Barabas, A. P. (1966). Brit. med. 7., 2, 682.

Goltz, R. W., and Hult, A. M. (1965). Sth. med. F. (Bgham, Ala.), 58, 848 .

Jackson, D. S., and Bentley, J. P. (1967). Collagen, vol. 2, edited by B.'S. Gould. London. In press.

Jansen, L. H. (1955). Dermatologica (Basel), 110, 108.

Jansen, L. H. (1955). Dermatologica (Basel), 110, 108. f. Amer. med. Ass., 194, 1011 .

McFarland, W., and Fuller, D. E. (1964). New Engl. F. Med., 271, 1309. McKusick, V. A. (1966). Heritable Disorders of Connective Tissue, 3rd ed. St. Louis.

Mories, A. (1960). Scot. med. 7., 5, 269.

Sxmundsson, J. (1956). Acta med. scand., Suppl. No. 312, vol. 154 p. 399.

Wechsler, H. L., and Fisher, E. R. (1964). Arch. Path., 77, 613.

\section{Preliminary Communications}

\section{Increased Fibrinolytic Activity in Venous Blood of Hemiplegic Limbs}

Brit. med.7., 1967, 2, 613-615

In a study of fibrinolysis in the venous blood from hemiplegic patients an increased rate of fibrinolysis was observed in the blood obtained from the hemiplegic limb compared with that from the contralateral side.

\section{Material AND Methods}

Forty-seven estimations of euglobulin lysis time (E.L.T.) and 44 estimations of dilute blood clot lysis time (D.B.C.L.T.) were made on 21 consecutive hemiplegic patients admitted to an acute medical ward. Blood was collected by clean venepuncture with minimal stasis from both arm veins between 9 and 9.30 a.m. The patients were in bed and had had their breakfast. In 21 estimations blood was collected first from the hemiplegic arm and in the remainder first from the nonhemiplegic arm. Samples of $4.5 \mathrm{ml}$. of blood were immediately mixed with $0.5 \mathrm{ml}$. of $3.8 \%$ sodium citrate contained in chilled test-tubes. These were subsequently spun at approximately 1,500 r.p.m. for seven minutes, the centrifuge buckets for the plasma tubes having previously been cooled at $0^{\circ} \mathrm{C}$. All blood and plasma specimens were kept in melting ice, and tests were carried out within 30 minutes of obtaining the specimen. The euglobulin lysis time was then estimated by the method of von Kaulla (1963), slightly modified as follows: (1) all the procedures previous to the incubation of the clot were carried out at $0^{\circ} \mathrm{C}$., (2) after passage of $\mathrm{CO}_{2}$ the tubes were centrifuged for four minutes, and ( 3 ) euglobulin was clotted by the addition of $1 \mathrm{ml}$. of thrombin solution ( 2 units).

All estimations were made in duplicate. The dilute blood clot lysis time was estimated by the method of Fearnley et al. (1957), a camera being used to determine the end-point as described by Lackner and Goosen (1959). 